\title{
Efeitos de Panfletos Informativos sobre a Aids em Adolescentes ${ }^{1}$
}

\author{
Brigido Vizeu Camargo ${ }^{2}$ \\ Andréa Barbará \\ Universidade Federal de Santa Catarina
}

\begin{abstract}
RESUMO - Este estudo buscou responder se diferentes materiais informativos impressos (panfletos), sobre a transmissão do HIV, podem favorecer ou dificultar o conhecimento desta doença e a atitude frente ao preservativo em adolescentes do ensino médio. Participaram 300 estudantes de escolas públicas e particulares das cidades de Florianópolis, Itajaí e Balneário Camboriú. Utilizaram-se três tipos de panfletos (A - Adolescência e aids; B - Adolescência, drogas e aids; C - Adolescência, sexualidade e aids), e três questionários (antes, após a leitura de panfletos e 10 dias depois). Para a análise empregou-se o teste de diferença entre médias ( $t$ de Student) e a análise de variância (MANOVA), através do programa informático SPSS 11.1. Os dados indicaram a existência de impactos positivos da leitura dos panfletos no conhecimento, mas em relação à atitude ao preservativo não houve alterações significativas. Pode-se avaliar como positiva a utilização de panfletos como estratégias preventivas frente à aids.
\end{abstract}

Palavras-chave: aids; conhecimento; atitude; preservativo; adolescentes.

\section{Effects of Informative Leaflets About AIDS on Adolescents}

\begin{abstract}
This study aimed at answering if different printed informatives on HIV transmission (leaflets) can facilitate or make difficult the knowledge about the disease and the attitude towards condoms among high school students. Three hundred secondary students from public and private schools from the cities of Florianópolis, Itajaí and Balneário Camboriú participated. Three types of leaflets were used (A - Adolescence and AIDS; B - Adolescent, drugs and AIDS; C - Adolescence, sexuality and AIDS), and three questionnaires (before, after reading the leaflets and 10 days later). The test of differences between means (Student's $t$ ) and analysis of variance (MANOVA) were employed for data analysis, through the software SPSS 11.1. The data indicated the existence of positive impacts of the reading of leaflets on AIDS knowledge, but there were no significant changes concerning the attitude towards condoms. The use of informative leaflets as preventive strategies against AIDS can be evaluated as positive.
\end{abstract}

Key words: AIDS; knowledge; attitude; condom; adolescents.

O impacto social causado pela aids é consequiência do aumento da incidência de casos, especificamente em categorias inicialmente não associadas com a doença, como, por exemplo, os grupos de transmissão heterossexual, de mulheres e de idades cada vez mais jovens, ou seja, adolescentes. De acordo com o Ministério da Saúde, no ano de 2003, foram notificados 9758 casos de aids. Deste total, $17 \%$ são adolescentes e adultos jovens, na faixa etária dos 13 aos 24 anos. No caso da aids, a informação fornecida, para provocar uma redução de comportamentos de risco, deve incluir conhecimentos específicos a respeito da transmissão e prevenção (D'Amorin, 2002). Portanto, os processos de comunicação são um valioso e importante instrumento para informar e prevenir a população do risco desta epidemia.

A comunicação social influi na determinação das atitudes dos destinatários, com suas mensagens, intervindo de modo essencial na formação, delineamento e modificação da concepção de mundo pelo homem. Ela desempenha papel

1 Pesquisa realizada pelo Laboratório de Psicossociologia da Comunicação e da Cognição Social (LACCOS), da Universidade Federal de Santa Catarina, através de convênio firmado com o Fundo Nacional de Saúde. Trabalho apresentado na III Jornada Internacional e I Conferência Brasileira sobre Representações Sociais (Rio de Janeiro, 2003).

2 Endereço: Av. Salvador Di Bernardi n ${ }^{\circ}$ 505, ap. 1102, São José, SC, Brasil, 88101-260. E-mail: bcamargo@cfh.ufsc.br relevante no processo de socialização dos adolescentes, ao proporcionar-lhes representações e noções sobre os valores socialmente aceitos, relativos às atividades humanas, e aos objetos materiais e espirituais importantes para um dado grupo ou sociedade (Maletzke, 1976).

Os efeitos da comunicação social podem influir nas atitudes e valores, no conhecimento e no comportamento dos destinatários (Maletzke, 1976; Wolf, 1999). Este estudo está voltado, sobretudo aos efeitos sobre o conhecimento relativo à aids e sobre a atitude frente ao uso do preservativo.

Estudos realizados em relação ao uso do preservativo (Albarracín, Jonhson, Fishbein \& Muelliriule; 2001; Antunes, Peres, Paiva, Stall \& Hearst, 2002; Cecil \& Zimet, 1998) detectaram que a maioria dos adolescentes possui pouca intenção de utilizá-lo. Os fatores que influenciam a decisão do sexo protegido (Gebhardt, Kuyper \& Greunsven, 2003) dependem da relação existente entre os parceiros. O principal fator para não uso do preservativo é a presença de parceiro fixo (Jiménez, Gotlieb, Hardy \& Zaneveld, 2001). De acordo com Apter, Cacciatore e Hermanson (2004) as circunstâncias que influenciam o não uso do preservativo, são: o preço do preservativo, a dificuldade em comprá-lo, experiências sexuais não planejadas, o uso de álcool e drogas, e a propensão para assumir riscos.

Um estudo realizado por Tamayo, Lima, Marques e Martins (2001), com 300 estudantes da Universidade de 
Brasília e com o objetivo de verificar se as prioridades axiológicas das pessoas influenciam o uso de preservativo no relacionamento sexual, constatou que seu uso se relaciona negativamente com as crenças que se fundamentam na diminuição da sensação sexual e de que propor ao parceiro(a) o uso de camisinha demonstra falta de confiança nele(a); e positivamente com a opinião que quem estima a sua saúde deve usá-la regularmente.

MacDonald, MacDonald, e Fong (2000), testando a teoria da miopia alcoólica, relacionando o álcool à excitação sexual e à intenção de usar o preservativo em rapazes universitários (de 18 e 19 anos), demonstrou que o álcool interfere significativamente na decisão do (não) uso do preservativo. Outro fator destacado por pesquisadores (Betts, Peterson \& Huebner, 2003; Pascual, 2002) é que os meninos possuem mais resistência ao uso do preservativo que as meninas.

Algumas pesquisas (Campbell, Peplau \& DeBro, 1992; Wilson, Manual \& Lavelle, 1991) indicam a existência de crenças e atitudes negativas em relação ao uso de preservativo, no sentido que esta medida interfere na harmonia do encontro sexual e afeta negativamente a disposição sexual.

Os sistemas de valores envolvem atitudes específicas organizadas segundo uma estrutura hierárquica. As atitudes, em geral, orientam o comportamento do homem. Mas não é rara a convivência de comportamentos contrários às atitudes, bem como mudanças de atitude que não afetam os comportamentos a ela associados. Conforme Triandis, atitude pode ser definida da seguinte forma:

\section{As atitudes envolvem o que as pessoas pensam, sentem e como elas gostariam de se comportar em relação a um objeto atitu- dinal. O comportamento não é apenas determinado pelo que as pessoas gostariam de fazer, mas também pelo o que elas pensam que devem fazer, isto é, normas sociais, pelo o que elas geralmente têm feito, isto é, hábitos, e pelas conseqüên- cias esperadas de seu comportamento. (conforme citado em Rodrigues, Assmar \& Jablonski, 2002, p. 102)}

A operacionalização desse estudo remete-se a consideração de uma conceituação mais delimitada do termo "efeito", este abrange todos os processos que ocorrem na fase póscomunicativa (como consequiência da comunicação social) e por outro lado, todos os modos de comportamento que resultam da atenção dada pelo destinatário às mensagens da comunicação social, na fase comunicativa propriamente dita (Maletzke, 1976). Conforme Wolf (1999), este conceito pragmático de efeito compreende uma parte da fase comunicativa (o comportamento de comunicação) assim como toda a fase pós-comunicativa. Nesse contexto, admite-se a influência da comunicação social, na medida em que ela ajuda a estruturar a imagem da realidade social, a organizar elementos novos dessa mesma imagem e a formar opiniões e crenças novas.

O processo de comunicação envolve uma percepção seletiva seguida de uma interpretação determinada logo após a exposição de conteúdo. As pessoas percebem, absorvem e lembram o conteúdo de diferentes maneiras, de acordo com certos fatores mediadores, como seus desejos, motivações e atitudes anteriores (Maletzke, 1976). Estes fatores caracterizam-se como referentes ao aspecto psicológico dos seres humanos que afeta a sua exposição a campanhas e a sua recepção da mensagem. Todavia, também entra em jogo fatores relativos aos aspectos psicossociais e sociais, e aqui se reteve dois deles, quais sejam: a condição de gênero do destinatário (sexo masculino e feminino) e sua situação sócio-econômica (escola pública ou particular). Primeiramente, em matéria de aids, o sexo dos destinatários das mensagens preventivas tem um papel importante, na medida em que ele está associado culturalmente e historicamente com atitudes e valores que hierarquizam e separam os homens e as mulheres (Godelier, 1980; Heller, 1980). Em se tratando de gênero, um estudo, com a mesma amostra do presente trabalho, mas com foco na restituição de mensagens informativas, detectou que as meninas restituem mais que os meninos, independente do tipo de mensagem transmitida (Hias \& Camargo, 2003). O segundo fator que, igualmente interessa, decorre de observações que indicam associação da pobreza, dificuldade de acesso aos cuidados com a saúde, violência e exploração sexual de menores com a vulnerabilidade dos adolescentes diante do HIV (Santos \& Santos, 1999).

Um fenômeno que pode ser revelador para o estudo da discrepância entre a aprendizagem e a modificação de atitudes é o chamado "efeito letárgico"; em não raras ocasiões, os efeitos de uma mensagem são relativamente pequenos imediatamente após sua recepção. Uma outra questão muito importante em torno da problemática dos efeitos é a que se ocupa das relações entre atitudes e o correspondente comportamento, ou seja, a força motivadora inerente às atitudes (Maletzke, 1976). Este fenômeno leva-nos a necessidade de distinguir operacionalmente efeito em curto e médio prazo. $\mathrm{O}$ primeiro refere-se ao tempo imediatamente posterior a exposição do destinatário à mensagem, o segundo envolve um distanciamento temporal de alguns dias ou de algumas semanas após a leitura do material informativo. Percebe-se pela leitura de Berelson (1969) que este já considerava, na década de 50, a importância da distinção dos efeitos a curto e longo prazo, uma vez que os primeiros, por serem mais facilmente operacionalizados, eram os mais estudados, no entanto pela diferença entre estes dois tipos de influência, os resultados das pesquisas não poderiam ser transferidos do primeiro para o segundo tipo.

\section{A recepção da informação preventiva da aids nos adolescentes}

A opção por trabalhar com adolescentes deve-se à vulnerabilidade deste grupo em contrair o vírus HIV, pois o início da atividade sexual, cada vez mais precoce, e a curiosidade pelas drogas, os fazem mais presentes na suscetibilidade à epidemia (Taquette, Vilhena \& Paula, 2004). O conceito de vulnerabilidade, desenvolvido por Mann, Tarantola e Netter (1993), classifica como vulnerabilidade biológica todo e qualquer indivíduo, que uma vez exposto ao vírus através do ato sexual ou do contato com sangue contaminado, pode tornar-se HIV positivo.

De acordo com Devos-Comby e Salovey (2002), a implementação de campanhas destinadas a grupos vulneráveis ao HIV, com informações sobre as formas de prevenção e transmissão diminui os comportamentos de risco. No Brasil, as campanhas de prevenção destinadas especialmente 
aos jovens são poucas. Conforme dados do Ministério da Saúde, até hoje, houve apenas duas campanhas realizadas especificamente para o público adolescente, uma em 1994 e a outra em 2003. O calendário de prevenção da aids na mídia envolve poucas inserções nas rádios e na televisão, geralmente na época do Carnaval, e mesmo assim dirigidas ao público em geral.

Um estudo realizado por Roso (2000), analisando a recepção de propagandas de prevenção da aids veiculadas na televisão, por mulheres com idades entre 18 a 51 anos, indicou que este meio é uma importante fonte de informações relacionadas à aids, contudo as propagandas nela veiculadas não estimulam o uso do preservativo.

Camargo Jr. (1999) constata que o impacto das ações preventivas da Coordenação Nacional DST/AIDS não tem sido avaliado. Segundo este pesquisador, isto se deve tanto à natureza do problema quanto ao fato dos agentes não disporem de quadro teórico e metodológico para esta avaliação. O autor aponta ainda para a necessidade do programa nacional buscar maior colaboração com os centros de pesquisa científica para os programas de prevenção.

Conforme Paiva, Peres e Blessa (2002), a prevenção precisa estar integrada a idéia de cidadania e direitos, bem como relacionadas aos temas da sexualidade, uso de drogas e diferenças de gênero. Outro fator destacado pelos autores é que a mensagem informativa deve ser transmitida em uma linguagem clara, franca e acessível, principalmente desprovida de preconceitos e/ou idéias que não possuam respaldo científico, e que por isso, não desenvolve a devida conscientização sobre a necessidade da prevenção.

Carlini-Cotrin, Gazal-Carvalho e Gouveia (2000) detectaram que uma significativa proporção de jovens estudantes, de escolas públicas e particulares da região metropolitana da cidade de São Paulo, engajava-se em comportamentos de riscos. Nas escolas públicas os comportamentos mais freqüentes foram andar de motocicleta sem capacete e não utilizar o preservativo na última relação sexual; já nos alunos das escolas particulares, o uso de substâncias psicoativas, principalmente o álcool, era mais freqüente.

Este estudo partiu de duas pesquisas anteriores: uma delas consistia de uma análise comparativa dos elementos centrais das representações sociais de estudantes universitários sobre a aids (Camargo, 2000) e a outra de uma análise descritiva e compreensiva das relações entre conhecimento e adoção de condutas preventivas diante do vírus HIV entre adolescentes de ensino médio (Camargo, Botelho \& Souza, 2001). Os resultados indicaram problemas quanto ao conhecimento sobre as formas de transmissão e a existência da necessidade de material apropriado ao adolescente para a difusão das informações sobre DST/aids.

Sabe-se que um dos fatores relevantes para a prevenção da aids é o conhecimento que os adolescentes têm sobre a epidemia. A maioria dos estudantes pesquisados por Camargo e cols. (2001) demonstrou conhecer os modos de transmissão do HIV, pelas vias sexual e sangüínea. Eles dizem ter obtido informações sobre a doença, principalmente pelos veículos televisivos e do ambiente escolar; folhetos informativos e família também merecem lugar de destaque.

Uma pesquisa anterior (Camargo, 2000), sugeriu-se que a variável "sexo" indicava inserções sociais diferentes diante da sexualidade humana e do uso de drogas injetáveis (UDI). Isto gerou a necessidade de analisar como o sexo do sujeito interfere na retenção dos conteúdos informativos escritos de prevenção da aids. O fato dos rapazes e das moças se posicionarem de forma tão diferenciada quanto às relações sexuais e ao UDI não seriam obstáculos para as campanhas de prevenção da aids? A diferenciação das mensagens informativas escritas (panfletos) pela ênfase nos modos de transmissão do vírus facilitaria a retenção da informação? Assim, o tipo de mensagem e o sexo do destinatário foram considerados fatores importantes neste estudo.

A condição sócio-econômica dos adolescentes é outra variável utilizada por este estudo, pois se apresenta associada, como mencionamos anteriormente, à vulnerabilidade diante do HIV. Ela foi operacionalizada na segmentação por turnos: noturno (escola pública) ou diurno (escola particular) das classes dos participantes da pesquisa.

Assim sendo, esta pesquisa preocupou-se em estudar o impacto das informações preventivas sobre a aids, por meio de panfletos informativos, no conhecimento e atitudes relativos à transmissão e proteção do HIV.

\section{Método}

\section{Caracterização da Pesquisa}

Trata-se de um estudo experimental de campo. Utilizouse um delineamento fatorial que envolve a relação de uma variável independente "tipo de panfleto", e duas de controle "sexo do participante" e "turno escolar", com duas variáveis dependentes, "conhecimento sobre transmissão do HIV" e "atitude sobre o preservativo". Foram considerados ainda dois intervalos de tempo: logo após a leitura da mensagem (curto prazo) e 10 dias após esta leitura (médio prazo).

\section{Participantes}

A amostra compreendeu 300 estudantes do $2^{\circ}$ ano do ensino médio das cidades de Florianópolis, Itajaí e Balneário Camboriú. Participaram duas escolas (uma pública e uma particular) em cada uma das cidades de Florianópolis e Itajaí, e uma pública em Balneário Camboriú. Do total de participantes, metade (150) frequientava escola pública noturna e a outra metade escola particular diurna, sendo 75 do sexo masculino e 75 do sexo feminino. Dos 75 alunos de cada sexo e escola, cada 25 alunos leram um tipo de panfleto (A, B ou C). Foram acrescentados 50 alunos à amostra inicial, também do $2^{\circ}$ ano do ensino médio de escola pública noturna da cidade de Florianópolis, para constituírem o grupo controle.

\section{Material e Instrumentos}

Utilizaram-se três panfletos experimentais, cada panfleto possuiu seis páginas que apresentam o mesmo número de palavras.

O panfleto A (Adolescência e aids) não enfatiza nenhum meio de transmissão do vírus HIV; o B (Adolescência, drogas e a aids) relaciona a transmissão da aids com as drogas; e o C (Adolescência, sexualidade e aids) relaciona a transmissão aids com doenças sexualmente transmissíveis (DST). Os três 
tipos panfletos são idênticos nas páginas 3, 4 e 5. A página 3 apresenta as formas de transmissão do HIV, como não se transmite este vírus e como se prevenir da aids. A página 4 explica a utilização do preservativo e a página 5 fornece os telefones de Centros de Testagem e Aconselhamento das cidades que fazem parte do estudo ou próximas.

O conteúdo das páginas 1 e 2 dos três panfletos apresenta diferenças. Na página 1 temos três partes: a) introdução, onde a adolescência é relacionada a aids de três maneiras (no panfleto A esta relação é geral, no B ela enfatiza a transmissão ligada às drogas e no $\mathrm{C}$ a transmissão sexual é o ponto de ligação); b) conceito de aids, consiste numa breve explicação sobre o que é a doença e o significado das siglas aids e HIV e c) dados epidemiológicos, mostra-se o número de adolescentes, meninos e meninas, na faixa etária de 13 a 19 anos, infectados pelo vírus HIV no Brasil e proporção em função de formas de contaminação (no panfleto A apresentase juntamente a transmissão sexual e por UDI, no B aquela por UDI e no $\mathrm{C}$ a sexual).

Na página 2, cada tipo de panfleto apresenta conteúdos conforme a ênfase dada ao modo de transmissão do HIV. O panfleto do tipo A foi composto da seguinte maneira: conceito de DST, tipos, relação de DST com a aids, conceito de drogas, tipos de drogas, relação das drogas com a aids. O panfleto B prioriza a transmissão pelo UDI da seguinte forma: conceito de drogas, tipos, efeitos no organismo, relação das drogas com a aids. Já o panfleto C enfatiza a transmissão sexual do HIV e suas partes são: conceito de DST, tipos, sintomas e tratamento, relação de DST com a aids.

Os instrumentos empregados neste estudo foram três questionários auto-administrados em situação coletiva.

Os questionários foram construídos a partir dos instrumentos utilizados nos estudos anteriores de Camargo (1997, 1998, 2001), tendo como objetivos: a) fornecer dados sobre o conhecimento dos participantes sobre a transmissão da aids e sobre suas atitudes diante do preservativo e, b) o impacto do panfleto no conhecimento sobre a doença.

O primeiro questionário, prévio a leitura do panfleto, teve como intuito coletar dados para caracterizar os participantes, averiguar o que eles conheciam sobre a transmissão da aids e qual sua atitude sobre o preservativo (ver anexo). O segundo questionário, respondido depois da leitura do panfleto, abordava novamente questões sobre conhecimento da aids e apresentava pela segunda vez a escala de atitude sobre o preservativo, além de solicitar a opinião dos participantes em relação ao panfleto. O terceiro questionário, que foi aplicado 10 dias após a leitura do panfleto, buscou averiguar o destino que os jovens deram ao panfleto que lhes foi entregue, e ainda averiguar pela terceira vez o conhecimento sobre a aids e a atitude sobre o preservativo dos participantes.

A partir dos sete itens sobre o conhecimento da transmissão do HIV, construiu-se um indicador. Cada resposta correta a um item correspondeu a 1 ponto, e cada resposta incorreta ou declaração de que não sabia, não implicou ponto ao respondente. $\mathrm{O}$ índice consiste em um escore obtido pela adição dos pontos obtidos nos 7 itens, podendo assumir um valor mínimo de 0 e máximo de 7 . Trabalhou-se com as médias destes escores de cada grupo.

A atitude dos participantes sobre o preservativo foi medida por uma escala do tipo Likert com 4 pontos (ponto médio =
2,5), composta de 12 itens (ver Anexo). A consistência entre os itens restantes foi moderada $(\alpha=0,75)$. Para a obtenção do escore médio dos 12 itens considerados utilizou-se o método da tendência linear ao ponto, na estimação das médias nos itens onde respondentes assinalaram a modalidade "não sei" ou onde eles deixaram em branco.

\section{Procedimentos}

Primeiramente, foi estabelecido contato com a direção de cada escola e solicitada autorização para a realização da pesquisa. Nesta ocasião o projeto foi apresentado sob a forma de protocolo de estudo e explicado para as direções das escolas. As direções já dispunham de autorização dos pais de alunos para atividades de estudo e prevenção da aids. Este tipo de atividade faz parte das recomendações da Secretaria Estadual de Educação (Santa Catarina) para as escolas (implementação de conteúdos transversais). A coleta dos dados pertinentes a pesquisa foi acompanhada pelas respectivas orientadoras pedagógicas, principalmente a escolha das turmas participantes.

As experiências em campo foram aplicadas por seis pesquisadoras treinadas para tal fim. Foram realizados dois encontros com cada turma, num intervalo de tempo de dez dias entre eles. Utilizando-se três turmas em cada escola, uma para cada tipo de panfleto (A, B ou C), que passaram simultaneamente pela experiência.

O grupo controle não leu os panfletos, apenas respondeu dois questionários equivalentes ao primeiro e o terceiro.

\section{Análise dos dados}

Neste estudo, para a comparação de características dos estudantes em função do tipo de escola utilizou-se o teste de qui-quadrado; para a análise do efeito dos panfletos sobre o conhecimento dos participantes a respeito da aids e sobre suas respectivas atitudes diante do preservativo empregou-se o teste de diferença entre médias ( $t$ de Student) e a análise de variância (MANOVA), realizada por meio do programa informático SPSS 11.1.

\section{Resultados}

Os alunos que participaram deste estudo apresentaram média de idade de 16 anos e 3 meses, sendo que a idade mínima foi de 15 anos, enquanto a idade máxima atingiu os 26 anos. Mais da metade dos estudantes declarou ter experiência de trabalho remunerado: 51,5\%. Conforme esperado, a maioria dos alunos de escola pública noturna (72\%) teve este tipo de experiência, enquanto entre os alunos de escola particular uma minoria trabalhou ou trabalha com remuneração $(28 \%)$. Vale salientar que esta diferença mostrou-se significativa $\left(\chi^{2}\right.$ $=56,73 ; g l=1 ; p<0,01)$.

Dentre os alunos pesquisados em escolas públicas noturnas, $71 \%$ responderam estar namorando alguém, enquanto apenas 29\% dos alunos de escolas particulares diurnas possuíam namorado ou namorada. A diferença entre os participantes da escola pública e da escola particular foi estatisticamente significativa $\left(\chi^{2}=24,51 ; g l=1 ; p<0,01\right)$. 
Quase metade dos meninos declarou ter experiência sexual com penetração nos últimos 12 meses $(49,3 \%)$ e menos de $1 / 3$ das meninas reconheceram este tipo de experiência $(30,4 \%)$. Sob este aspecto os grupos experimentais utilizados neste estudo não apresentaram diferenças significativas. E entre os participantes que declararam ter experiência sexual nos últimos 12 meses, 92,2\% dos meninos indicaram ter utilizado o preservativo e, $51,6 \%$ das meninas responderam ter utilizado a pílula anticoncepcional.

Outro fator considerado neste estudo foi o uso de drogas, pois está associado direta ou indiretamente ao risco de ser contaminado pelo HIV. Os dados apontaram que os meninos $(72,3 \%)$ consumiram mais drogas do que as meninas $(46,6 \%)$. A droga mais utilizada por estes adolescentes foi o álcool (49\%). A comparação da proporção de meninos (49\%) que ficaram bêbados nos últimos 12 meses com a das meninas $(23,3 \%)$ apresenta diferença significativa $\left(\chi^{2}=20,89 ; g l=\right.$ $1 ; p<0,01)$.

\section{Efeitos das mensagens no conhecimento sobre a transmissão do HIV}

A situação inicial do grupo controle e os grupos experimentais antes da leitura dos panfletos apresentaram diferenças entre os meninos (escore médio $=5,71$ ) e as meninas (escore médio $=5,58$ ), quanto ao conhecimento sobre a transmissão da aids, sobretudo no grupo designado para ler o panfleto tipo A e o grupo designado para não ler panfleto (o de controle). Mas estas diferenças não foram estatisticamente significativas $\left(F_{(3,199)}=0,50 ; p=0,68-\right.$ N.S. $)$, o que resulta em considerar que os quatro grupos que participaram da experiência tinham nível de conhecimento equivalente sobre a transmissão da aids.

Compararam-se os escores médios obtidos pelos participantes do grupo de controle no primeiro dia e 10 dias após, para examinar se houve efeito de medidas repetidas. Inicialmente o escore foi de 5,49 e 10 dias depois ele diminuiu para 5,26. Esta diferença foi significativa $(t=2,09 ; g l=49$; $p<0,05)$, mas no sentido contrário aquele esperado para os grupos que leram o panfleto.

Para verificar o suposto impacto do tipo de panfleto sobre o conhecimento relativo à transmissão da aids (Índice de conhecimento sobre a aids - ICT) foi utilizada uma análise de variância envolvendo um delineamento $2 \times 2 \times 3 \times 3$. Especificando, considerou-se o "sexo dos participantes" (masculino e feminino), o tipo de escola (particular ou pública), o tipo de panfleto lido (A, B ou C) e o escore relativo ao conhecimento sobre a aids (antes da leitura, após a leitura e 10 dias depois).

Verificou-se diferença significativa entre as três medidas sobre o indicador de conhecimento (variável "tempo"); $F_{(1,299)}=110,20 ; p<0,001$. A interação entre "tempo" e "tipo de escola" também afetou significativamente o ICT; $F_{(1,299)}=7,84 ; p<0,001$. E a interação entre "tempo", "tipo de panfleto" e "sexo" foi estatisticamente significativa; $F_{(2,299)}=3,30 ; p<0,05$.

Segundo a Figura 1, entre os participantes das escolas particulares, há um claro aumento dos escores relativos ao conhecimento entre o tempo 1 (antes da leitura) e o tempo 2 (após a leitura) para os três panfletos. Os efeitos em médio

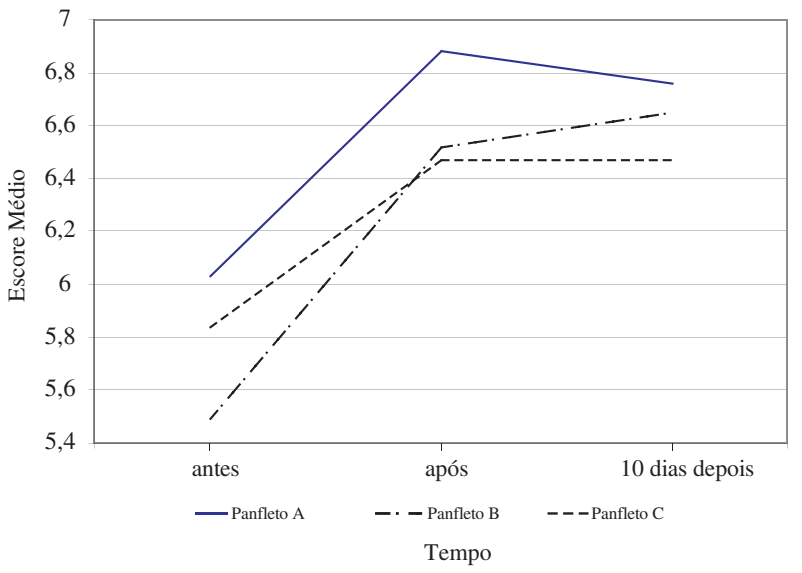

Figura 1. Mudanças em curto e médio prazo no escore médio de conhecimento sobre transmissão da aids em função da leitura dos panfletos nas escolas particulares $(N=150)$.

prazo (entre o tempo 2 e 3 ) é que são diferentes. O ganho de conhecimento é ligeiramente incrementado entre aqueles que leram o panfleto $\mathrm{B}$, mantido entre os que leram o panfleto $\mathrm{Ce}$ parcialmente diminuído entre os que leram o panfleto A. No entanto, entre a situação inicial e a situação final (tempo 1 e 3) sempre houve um ganho de conhecimento, independente do tipo de panfleto, o que é bem diferente do que se passou com o grupo controle. Como foi colocado, neste último houve diminuição no escore médio de conhecimento, o que o manteve abaixo dos 6 pontos, enquanto nos três grupos experimentais, com a introdução da variável "leitura de panfleto", superou-se os 6 pontos e isto se manteve em médio prazo.

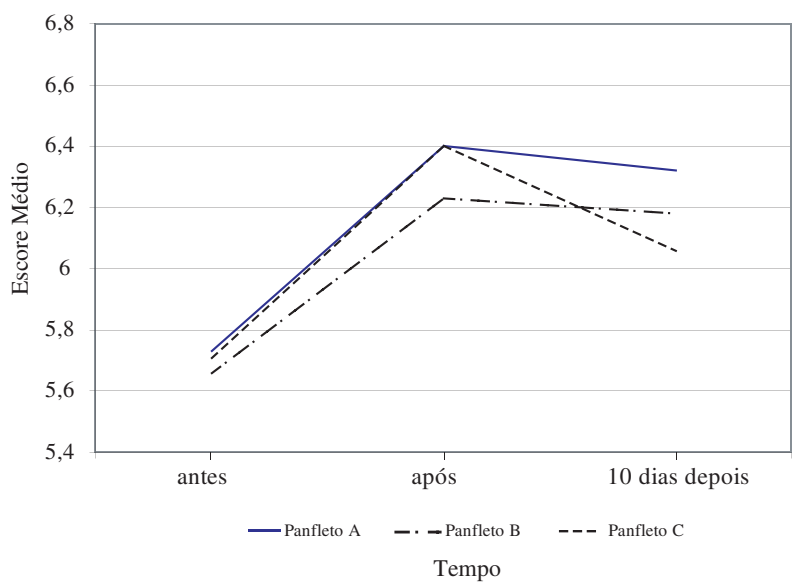

Figura 2. Mudanças em curto e médio prazo no escore de conhecimento sobre transmissão da aids em função da leitura dos panfletos nas escolas públicas $(N=150)$

Entre os participantes da escola pública, segundo a Figura 2, a comparação do tempo 1 e 2 indicou uma evolução similar àquela verificada naqueles participantes da escola particular, mas com menor intensidade. E houve perda do efeito positivo em médio prazo, entre aqueles que leram o panfleto tipo $\mathrm{C}$. $\mathrm{O}$ impacto positivo sobre os que leram os panfletos A e B se manteve após dez dias.

Ao analisar o impacto da mensagem em relação ao sexo dos participantes, conforme Figura 3, pode-se constatar que, entre os meninos, o efeito da leitura dos três tipos de 


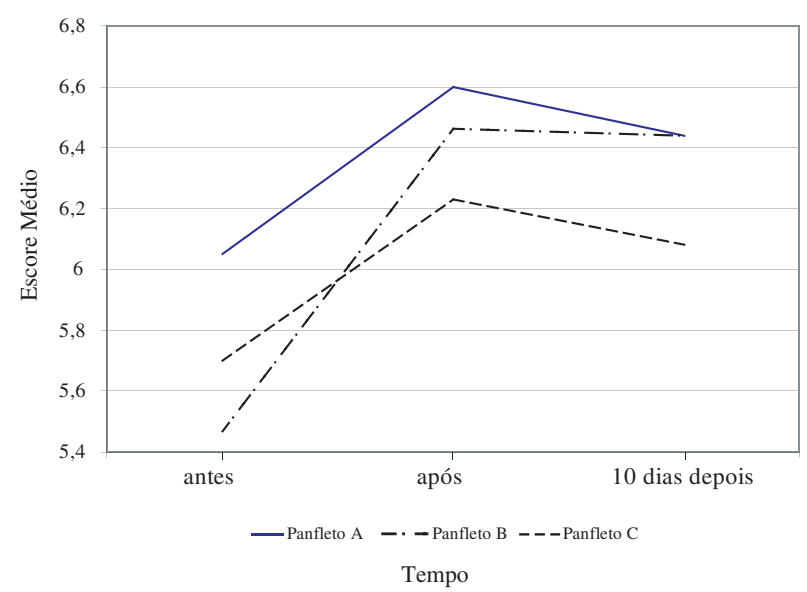

Figura 3. Mudanças em curto e médio prazo no escore de conhecimento sobre transmissão da aids em função da leitura dos panfletos do sexo masculino $(N=150)$.

panfletos, em curto prazo (logo após a leitura), é positivo no que se refere ao conhecimento sobre a transmissão da aids, mas ele é mais acentuado entre os leitores do panfleto tipo B, que relaciona adolescência, drogas e aids. Em médio prazo, o ganho de conhecimento, entre os leitores do panfleto B, é mantido. Já entre os leitores dos panfletos $\mathrm{A}$ e $\mathrm{C}$ há uma diminuição do escore de conhecimento. Este resultado está de acordo com as hipóteses deste estudo.

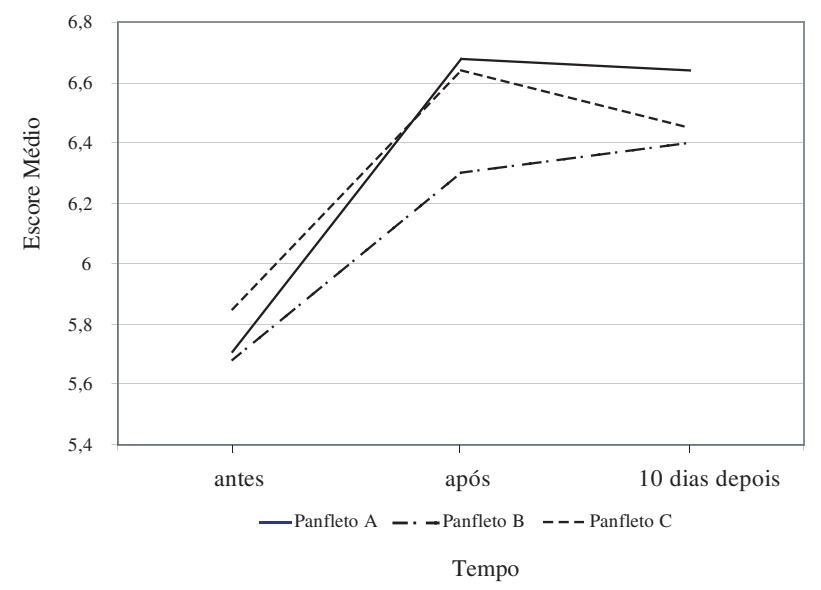

Figura 4. Mudanças em curto e médio prazo no escore de conhecimento sobre transmissão da aids em função da leitura dos panfletos do sexo feminino $(N=150)$.

Já entre as meninas, de acordo com a Figura 4, o aumento do conhecimento foi mais acentuado que entre os meninos, do tempo 1 para o tempo 2 (logo após a leitura), principalmente em relação ao panfleto A. Mas em médio prazo, enquanto as leitoras do panfleto tipo B apresentaram um incremento no ICT (Índice de conhecimento sobre a transmissão), nas leitoras do panfleto A houve uma estabilização e em relação aquelas do panfleto tipo $\mathrm{C}$ houve uma diminuição do referido índice após 10 dias da leitura.

Em se tratando de conhecimento sobre a aids, o panfleto tipo B apresentou mais impacto entre os meninos e o tipo A entre as meninas.

\section{As mensagens e a atitude sobre o preservativo}

Em todos os grupos, controle e experimentais, a atitude das meninas em relação ao uso do preservativo (escore médio $=3,28$ ) era mais favorável que a dos meninos (escore médio $=3,05$ ), embora esses dois escores (superiores a 2,5 pontos) indiquem que ambos os sexos têm uma atitude favorável ao objeto estudado.

A comparação da atitude inicial em relação ao preservativo dos quatro grupos (o de controle e os experimentais) indicou que as diferenças entre as médias não eram significativas $\left(F_{(3,199)}=1,01 ; p=0,50-\right.$ N.S. $)$ isto quer dizer que os quatro grupos apresentavam atitudes equivalentes antes da experiência.

As médias do grupo de controle no primeiro dia e dez dias após foram comparadas, com a finalidade de verificar o efeito de medidas repetidas. A primeira média (situação de base) foi de 3,20 e dez dias depois ela diminuiu para 3,16. Esta variação não é estatisticamente significativa $(t=1,01$; $g l=49 ; p=0,32-$ N.S.).

O efeito do tipo de panfleto sobre a atitude em relação ao uso do preservativo foi estudado utilizando-se também uma análise de variância, envolvendo o delineamento já explicitado para o estudo do conhecimento da transmissão da aids. As médias obtidas pelos grupos na escala de atitude eram três: antes da leitura, após a leitura e dez dias depois.

A interação entre "tempo" e "tipo de panfleto" afetou significativamente o escore de atitude sobre o preservativo (EAP), $F_{(2,289)}=4,34 ; p<0,05$. E a interação entre "tempo", "tipo de escola" também foi estatisticamente significativa, $F_{(1,289)}=4,79 ; p<0,05$.

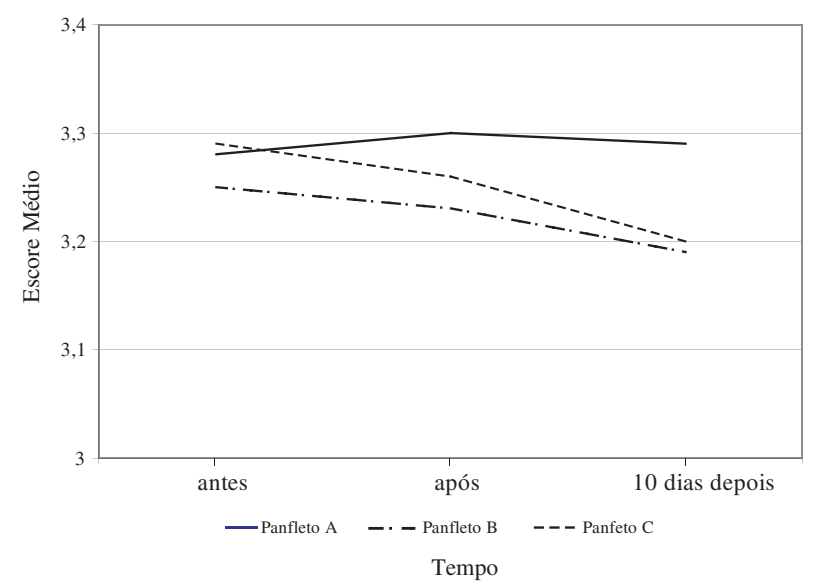

Figura 5. Mudanças em curto e médio prazo nas médias obtidas pelos participantes da escola particular na escala de atitude sobre o preservativo em função da leitura dos panfletos $(N=150)$.

Segundo a Figura 5, entre os alunos de escolas particulares, houve um discreto aumento no escore médio relativo à atitude sobre o preservativo, entre o tempo $1 \mathrm{e} o$ tempo 2 , somente para os leitores do panfleto tipo A; e em médio prazo esta média foi mantida. Já para os leitores dos panfletos B e C ocorreu uma diminuição das médias obtidas na escala de atitude. A leitura destes dois últimos panfletos diminuiu a "favorabilidade" da atitude dos participantes frente ao uso do preservativo. 


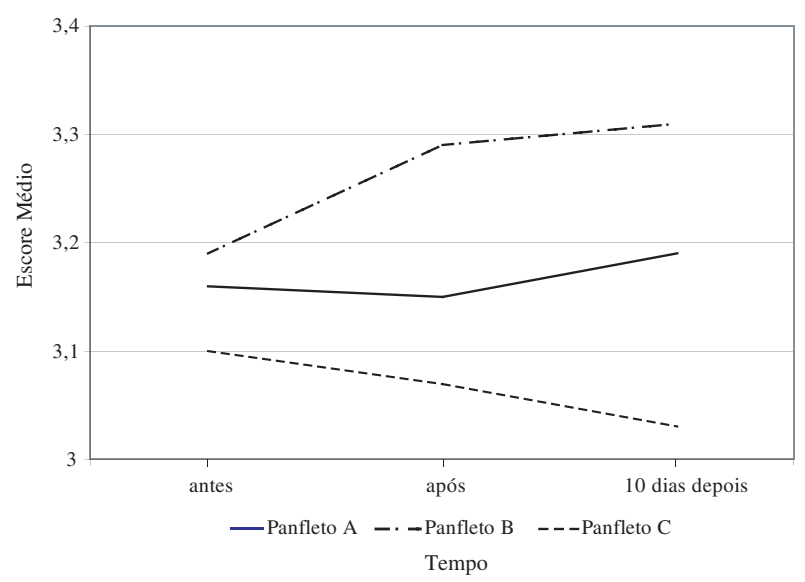

Figura 6. Mudanças em curto e médio prazo nas médias obtidas pelos participantes da escola pública na escala de atitude sobre o preservativo em função da leitura dos panfletos $(N=150)$.

Em se tratando dos alunos das escolas públicas, o panfleto tipo B interferiu positivamente, em curto e médio prazo, na atitude sobre o preservativo, como mostra a Figura 6. No caso das escolas particulares, a leitura do panfleto tipo A deixou a média estável, e a leitura do panfleto tipo $\mathrm{C}$ diminuiu a média obtida na escala.

\section{Discussão}

Os resultados apontam que o conhecimento sobre a transmissão da aids, nas escolas particulares, melhorou entre os leitores do panfleto B (Adolescência, drogas e aids) do que do panfleto A e C. Já nas escolas públicas, o panfleto A (Adolescência e aids) obteve mais efeito positivo. Em relação ao sexo dos participantes, o impacto positivo do panfleto tipo $\mathrm{B}$, sobre o conhecimento relativo a transmissão da aids, foi mais evidente entre os meninos. Entre as meninas, o panfleto A produziu um melhor resultado.

Em se tratando da atitude relacionada ao uso do preservativo, houve uma inversão em relação aos resultados sobre o conhecimento da aids. O panfleto A (Sexualidade, adolescência e aids) teve mais impacto positivo nas escolas particulares e o panfleto B (Adolescente, drogas e aids) nas públicas.

Os dados examinados demonstram a existência de impacto positivo da leitura dos panfletos no conhecimento da aids, mas em relação à atitude frente ao preservativo não houve alterações significativas, e, em alguns casos, a favorabilidade frente ao objeto foi diminuída.

Os destinatários das mensagens preventivas (panfletos informativos) apresentaram condutas arriscadas em relação à contaminação pelo HIV. Este risco apresentou-se diferenciado em função da condição sócio-econômica dos adolescentes, relativamente operacionalizada pela comparação entre os tipos de escola. A maioria dos estudantes de escolas pública inicia sua atividade sexual mais cedo e têm parceiros (a) fixos (as), ou seja, namoram, fato que várias pesquisas (Apter \& cols., 2004; Gebhardt \& cols., 2003; Jiménez \& cols., 2001) associam à diminuição do uso do preservativo.

Já em relação aos estudantes das escolas particulares, o risco se expressa prioritariamente sob a forma do uso abusivo de drogas, principalmente o álcool, que conforme estudos anteriores (Carlini-Cotrin \& cols., 2000; Taquette \& cols., 2004) é um fator complicador para a decisão pelo uso do preservativo e sua implementação.

Existem várias razões para a ocorrência de comportamentos de risco (Apter \& cols., 2004). Um dos fatores levados em consideração é a desinformação, na medida em que os adolescentes parecem desconhecer fatores de risco do HIV e métodos de prevenção.

No entanto, a leitura do material informativo promoveu uma diminuição na favorabilidade da atitude frente ao preservativo. O contato dos estudantes com a mensagem preventiva desperta interesse, mas em vista destas condutas de risco, possivelmente suscitam também preocupação. Podese pensar em duas hipóteses para explicar esse resultado. A primeira seria que a leitura dos panfletos sobre a aids tenha gerado medo, e que este sentimento tenha propiciado aos participantes uma estimativa mais realista de suas atitudes frente à adoção de medidas preventivas (uso do preservativo). A segunda hipótese seria que o próprio ganho informacional, ao alterar o componente cognitivo da atitude em relação à necessidade do uso de preservativos e quanto ao seu modo de emprego, tenha influído no componente afetivo da mesma (medido pela escala de Likert), de modo a obter coerência.

Os resultados, sobretudo aqueles referentes ao ganho de conhecimento, indicam que o contato com novas informações, adaptadas ao público destinatário das mesmas, torna-se relevante como instrumento de prevenção a ser disponibilizado nas escolas, instituições e centros de aconselhamentos para DST/aids. No entanto, apenas aumentar o nível de informação sobre a transmissão do HIV, e, sobre a necessidade de usar o preservativo, parece não ser suficiente para garantir um efetivo comportamento de proteção. Seria preciso, além de disponibilizar informações, oferecer programas de educação sexual, que possam aumentar a capacidade de tomada de decisão e desenvolver práticas mais seguras.

Mesmo assim, pode-se avaliar como positiva a utilização de panfletos informativos como de formulação de estratégias preventivas frente à aids. Portanto, em vista desses resultados, sobretudo do bom rendimento informacional do panfleto A, além dos pontos específicos vantajosos dos panfletos $\mathrm{B}$ e C, bem como dos limites destes dois últimos tipos de panfleto, optou-se em elaborar um único tipo de panfleto destinado aos adolescentes do nível médio de ensino. Este último panfleto resultou de uma reestruturação do panfleto experimental tipo A, considerando os desempenhos dos panfletos experimentais tipo B e C (envolvendo informações sobre drogas e sobre DST). E ele foi oferecido ao público jovem, com conteúdos iguais, mas com capas diferentes nas suas cores e desenho, de acordo com o sexo do público alvo.

\section{Referências}

Albarracín, D., Jonhson, B. T., Fishbein. M. \& Muelliriule, P. A. (2001). Theories of reasoned action and planned behavior as models of condom use: A Meta-Analysis. Psychological Bulletin, 127 (1), 142-161.

Antunes, M. C., Peres, C. A., Paiva, V., Stall, R. \& Hearst, N. (2002). Diferenças na prevenção da Aids entre homens e mulheres jovens de escolas públicas em São Paulo, SP. Revista de Saúde Pública, 36(4), 88-95. 
Apter, D., Cacciatore, R. \& Hermanson E. (2004). Adolescent contraception. International Congress Series, 1266, 81-89.

Berelson, B. (1969). La comunicación colectiva y la opinión pública. Em W. Scharamm (Org.), Processo y efectos de la comunicación colectiva (pp. 296-308). Quito: C.I.E.S.P.A.L.

Betts, S. C., Peterson, D. J. \&. Huebner, A. J. (2003). Zimbabwean adolescents' condom use: what makes a difference? Implications for intervention. Journal of Adolescent Health, 33(3), 165171.

Camargo Jr., K. R. (1999). Políticas públicas e prevenção em HIV/ AIDS. Em R. Parker; J. Galvão \& M. S. Bessa (Orgs.), Saúde, desenvolvimento e política: Respostas frente a AIDS no Brasil (pp. 227-262). São Paulo: ABIA/Editora 34.

Camargo, B. V. (1997). Communication et prévention du sida: études sur le rapport entre l'information télévisuelle, les représentations sociales et la pratique préventive chez les jeunes lycéens. Thèse de Doctorat en Psychologie Sociale, École des Hautes Études en Sciences Sociales, Paris.

Camargo, B. V. (1998). Estudo do conhecimento, das atitudes e dos aspectos de comunicação relativos à prevenção da AIDS dos estudantes das 3 as série da Escola técnica Federal de Santa Catarina (relatório técnico de pesquisa.). Florianópolis: UFSC/LACCOS.

Camargo, B. V. (2000). Sexualidade e representações sociais da Aids. Revista de Ciências Humanas. Especial temática, 3, 97-110.

Camargo, B. V., Botelho, L. J. \& Souza, E. S. B. (2001). AIDS, sexualidade e atitudes sobre a proteção contra o HIV: Um estudo descritivo com adolescentes do nível médio da rede de ensino (relatório técnico de pesquisa). Florianópolis: UFSC/ LACCOS.

Campbell, S. M., Peplau, L. A. \& DeBro, S. C. (1992). Women, men and condoms: Attitudes and experiences of heterosexual college students. Psychology of Women Quarterly, 16(3), 273-288.

Carlini-Cotrim, B., Gazal-Carvalho, C. \& Gouveia, N. (2000). Comportamentos de saúde entre jovens estudantes das redes pública e privada da área metropolitana do Estado de São Paulo. Revista de Saúde Pública, 34(6), 636-645.

Cecil, H. \& Zimet, G. D. (1998). Meanings assigned by undergraduates to frequency statements of condom use. Archives of Sexual Behavior, 27(5), 493-505.

D’Amorin, M. A. (2002). A prevenção da AIDS em universitários. Temas em Psicologia da SBP, 10(1), 53-62.

Devos-Comby, L. \& Salovey, P. (2002). Applying persuasion strategies to alter HIV - relevant thoungs and behavior. Review of General Psychology, 16(3), 287-304.

Gebhardt, W. A., Kuyper L. \& Greunsven G. (2003). Need for intimacy in relationships and motives for sex as determinants of adolescent condom use. Journal of Adolescent Health, 33(3), 154-164.

Godelier, M. (1980). As relações homem-mulher: O problema da dominação masculina. Civilização Brasileira III(26), 9-29.

Heller, A. (1980). O futuro das relações entre os sexos. Civilização Brasileira III(26), 49-61.

Hias, F. M. S. \& Camargo, B. V. (2003). Representações sociais e conhecimento sobre a aids: estudo experimental da restituição de informações preventivas lidas por adolescentes [Resumo]. Em Universidade do Estado do Rio de Janeiro (Org.), Resumos da III Jornada Internacional e I Conferência Brasileira sobre Representações Sociais (CD-ROM). Rio de Janeiro.
Jiménez, A. L., Gotlieb, S. L. D., Hardy, E. \& Zaneveld, L. J. D. (2001). Prevenção de doenças sexualmente transmissíveis em mulheres: Associação com variáveis sócio-econômicas e demográficas. Cadernos de Saúde Pública, 17(1), 55-62.

Maletzke, G. (1976). Sociologia de la comunicacion social. Quito: Época.

MacDonald, T., MacDonald, G., Zann, M. \& Fong, G. (2000). Alcohol, sexual arousal, and intencion to use condoms in young men: Applying alcohol myopia theory to risk sexual behaviors. Health Psychology, 19(3), 290-298.

Mann, J., Tarantola, D. J. M. \& Netter, T. W. (Orgs.). (1993). A AIDS no mundo. Rio de Janeiro: ABIA/IMS-UERJ/Relume Dumará.

Ministério da Saúde (2004). Dados e pesquisas em DST e Aids. Retirado em 29/06/2004, de http://www.aids.gov.br.

Paiva, V., Peres, C. \& Blessa, C. (2002). Jovens e adolescentes em tempos de Aids. Reflexões sobre uma década de trabalho de prevenção. Psicologia USP, 13(1), 55-78.

Pascual, S. L. (2002). Qualitative Assessment of a Campaign Promoting Condom Use among a Teenage and Young Adult Population in the Community of Madrid, Spain. Salud Publica, 76(2), 509-516.

Rodrigues, A., Assmar, E. M. L. \& Jablonski, B. (2002). Psicologia social. Petrópolis: Vozes.

Roso, A. (2000). Ideologia e relações de gênero: Um estudo de recepção das propagandas de prevenção da AIDS. Cadernos de Saúde Pública 16, 385-397.

Santos, V. L. \& Santos, C. E. (1999). Adolescentes, jovens e AIDS no Brasil. Brasília: Cadernos Juventude, Saúde e Desenvolvimento. Brasília: Coordenação Nacional de DST e AIDS.

Tamayo, A., Lima, A., Marques, J. \& Martins, L. (2001). Prioridades axiológicas e uso de preservativo. Psicologia: Reflexão $e$ Crítica, 14(1), 167-175.

Taquette, S. R., Vilhena, M. M. \& Paula, M. C. (2004). Doenças sexualmente transmissíveis e gênero: um estudo transversal com adolescentes no Rio de Janeiro. Cadernos de Saúde Pública, 20(1), 282-290.

Wilson, D., Manual, A. \& Lavelle, S. (1991). Psychological predictors of condom use to prevent HIV transmission among Zimbabwean. International Journal of Psychology, 26(6), 705-721.

Wolf, M. (1999). Teorias da comunicação. Lisboa: Presença. 


\section{Anexo - Questionário}

A. Responda se o vírus da aids pode ou não pode ser transmitido em algumas das seguintes situações: (Não esqueça de assinalar uma das três opções para cada item. Responda todos os itens).
Nas relações sexuais. $\operatorname{Sim}()$
Não ( )
Não sei ( )
Nos banheiros públicos $\operatorname{Sim}()$
Não ( ) Não sei ( )
Injetando droga com a seringa de outro(a)
$\operatorname{Sim}()$
Não ( ) Não sei ()
Recebendo sangue (transfusão sangüínea) $\operatorname{Sim}()$
Não ( ) Não sei ( )
Pela picada de um mosquito $\operatorname{Sim}($ )
Não ( ) Não sei ( )
Estando internado(a) num mesmo setor
do hospital que uma pessoa contaminada $\operatorname{Sim}()$
Não ( ) Não sei ( )
Doando sangue $\operatorname{Sim}($ )
Não ( ) Não sei ( )

B. A seguir apresentamos algumas situações. Imagine-se em cada uma delas e marque com um "X" a casa que melhor corresponda ao que você sente. Não existem respostas certas ou erradas. O que nos interessa é o que você realmente acha. (Não esqueça de dar sua opinião em todas as frases e marcar somente uma resposta para cada frase).

Opções: concordo totalmente, concordo, não concordo e nem discordo, discordo, discordo totalmente e não sei. Itens:

01. Quando a gente ama não tem vontade de usar o preservativo.

02. Para mim o preservativo tornou-se um reflexo, é natural utilizá-lo.

03. O preservativo tira a sensibilidade.

04. Se eu encontrar alguém numa boate... na excitação eu poderei esquecer o preservativo.

05. O preservativo corta o barato.

06. Eu teria preocupação com o que ele (a) pensaria de mim caso eu propusesse usarmos preservativo.

07. Depois das primeiras relações, quando a gente se conhece melhor, não é preciso utilizar preservativo.

08. Eu sei que existe risco, mas às vezes pode ser que eu não me importe.

09. Quando a gente escolhe bem nosso (a) parceiro (a) não precisa utilizar preservativo.

10. Eu acho que é difícil colocar o preservativo.

11. O preservativo nem sempre é seguro.

12. Eu não sei o momento que se deve falar sobre o preservativo. 